\title{
Random Spot Urine Protein/Creatinine Ratio Is Unreliable for Estimating 24-Hour Proteinuria in Individual Systemic Lupus Erythematosus Nephritis Patients
}

\author{
Lee A. Hebert ${ }^{a}$ Daniel J. Birmingham ${ }^{a}$ Ganesh Shidham ${ }^{a}$ Brad Rovin $^{a}$ \\ H.N. Nagarajab Chack-Yung Yu ${ }^{c}$ \\ Departments of ${ }^{a}$ Internal Medicine, ${ }^{b}$ Statistics and ${ }^{c}$ Pediatrics, The Ohio State University, Columbus, Ohio, USA
}

\section{Key Words}

SLE glomerulonephritis · Proteinuria · SLE flare

\begin{abstract}
Background: Recently the American Rheumatologic Association (ARA) recommended random spot urine protein/creatinine ratio $(\mathrm{P} / \mathrm{C})$ to monitor systemic lupus erythematosus (SLE) glomerulonephritis (GN). Shortly afterward, 2 works were published, designated Study 1 and Study 2, which are the only studies to test spot P/C in SLE GN. Here we evaluate Study 1 and Study 2, which came to different conclusions. Methods: Study 1 compared spot P/C to the P/C of intended 24 -hour collections $>50 \%$ complete, which reliably estimates 24 -hour proteinuria. Study 2 compared spot $\mathrm{P} / \mathrm{C}$ to the protein content of intended 24 -hour collections $>80 \% \mathrm{com}$ plete. To compare studies, Study 2 data were converted to P/C ratios. Results: Study 1 and Study 2 were found to be in agreement. Both showed that spot $\mathrm{P} / \mathrm{C}$ and 24 -hour $\mathrm{P} / \mathrm{C}$ were highly correlated, but only when compared over the entire $\mathrm{P} / \mathrm{C}$ range $(0-8.0)(r=0.842)$. Over the $\mathrm{P} / \mathrm{C}$ range $0.5-3.0$ (the most common $\mathrm{P} / \mathrm{C}$ range encountered in SLE GN), correlation was present, but concordance was poor, rendering random P/C ratio unreliable. Conclusions: Random spot P/C ratio is unreliable for detecting moderate proteinuria change.
\end{abstract}

For example, random spot P/C would not reliably diagnose British Isles Lupus Assessment Group (BILAG) Category A or $B$ proteinuric flares.

Copyright $\odot 2009$ S. Karger AG, Basel

\section{Introduction}

In chronic kidney disease (CKD), proteinuria magnitude is the strongest single predictor of glomerular filtration rate (GFR) decline. Furthermore, the magnitude of proteinuria reduction predicts the benefit of antiproteinuria therapy. For example, for each $1.0 \mathrm{~g} /$ day reduction in proteinuria achieved by 4 to 6 months of antiproteinuria therapy, GFR decline is decreased by 1 to $2 \mathrm{ml} / \mathrm{min} /$ year [1-4]. Thus, accurate assessment of proteinuria trend is important in CKD management [4-6].

In systemic lupus erythematosus (SLE) glomerulonephritis (GN), accurately assessing proteinuria change is especially important. For example, if baseline proteinuria is $\leq 200 \mathrm{mg} /$ day, an increase to $>1.0 \mathrm{~g} /$ day is a British Isles Lupus Assessment Group (BILAG) Category A renal flare [7]. In such patients increased steroid and/or immunosuppressive therapy is generally recommended. 
The gold standard to assess proteinuria is the protein content of an accurately collected 24-hour urine $[4,8]$. However, under collections $>40 \%$ or over collections $>25 \%$ are common [9-11]. Such collection errors are problematic because the error in estimating 24 -hour proteinuria from the protein content of intended 24-hour collections is directly proportional to the extent of over collection or under collection [11].

In an effort to simplify proteinuria assessment, Ginsberg reported in 1993 that the protein/creatinine $(\mathrm{P} / \mathrm{C})$ ratio of single void ('spot') specimens was highly correlated with 24-hour proteinuria [12]. Since then, numerous studies have confirmed Ginsberg's work $[5,6]$. Based largely on these correlational studies, the Kidney Disease Outcome Quality Initiative (K-DOQI) now recommends replacing 24-hour proteinuria testing with the $\mathrm{P} / \mathrm{C}$ ratio of random spot collections [8, 10]. This K-DOQI 'Level A' recommendation [10] has also been adopted by the Renal Disease Subcommittee of the American College of Rheumatology (ACR) [13].

Recently, we reported that the high correlation coefficients between spot urine $\mathrm{P} / \mathrm{C}$ ratio and 24-hour proteinuria are largely because these measures were compared over a wide range of values (e.g., a $\mathrm{P} / \mathrm{C}$ ratio $0-8$ ) [5] and correlation coefficient is extremely sensitive to the range of values being compared [14]. Over the sub-nephrotic range $(\mathrm{P} / \mathrm{C}$ ratio $0.5-3.0)$, which is the most common range encountered in CKD and in SLE GN patients $[11,15]$, a different picture emerges. In the sub-nephrotic range, random spot urine $\mathrm{P} / \mathrm{C}$ ratio appears to be only weakly related to 24 -hour proteinuria [5]. To clarify this issue in SLE GN, we studied the patients followed prospectively in the Ohio SLE Study (OSS). We compared random spot urine $\mathrm{P} / \mathrm{C}$ ratios to the $\mathrm{P} / \mathrm{C}$ ratio of their corresponding intended 24-hour urine collections. The intended 24-hour urine collections selected for study were at least $50 \%$ complete, based on their creatinine content [11]. The rationale is that such collections provide $\mathrm{P} / \mathrm{C}$ ratios that are not significantly different from those of complete 24-hour collections (those with a creatinine content within $\pm 10 \%$ of that expected in a complete 24 -hour collection) [11]. We found that random spot urine $\mathrm{P} / \mathrm{C}$ ratio showed significant correlation with 24 -hour urine P/C ratio but only weak concordance, particularly over the $\mathrm{P} / \mathrm{C}$ range of $0.5-3.0$.

Shortly after our publication [11], Leung et al. [15] published a similar study. Our work was not available at the time of their publication. They concluded that random spot urine $\mathrm{P} / \mathrm{C}$ ratio is a reliable measure of 24 -hour proteinuria in SLE GN. However, their study did not spe- cifically address the reliability of the spot $\mathrm{P} / \mathrm{C}$ ratio in the 0.5-3.0 range. The present work compares our study [11] to that of Leung's [15]. Hereinafter, these studies are referred to as Study 1 and Study 2, respectively.

\section{Methods}

Study 1 involved 64 OSS patients with International Society of Nephrology/Renal Pathology Society ISN/RPS Class 3, 4, or 5 SLE GN [16-18]. Random spot urines were collected at each of the bimonthly OSS visits. The paired 24-hour urines were collected 24 to $48 \mathrm{~h}$ before the OSS visit. To determine the completeness of each intended 24-hour collection, the following ratio was calculated: (measured creatinine content (M)/expected creatinine content (E)) using the Cockcroft-Gault (C-G) equation, where $\mathrm{E}=$ $(140$ - age $) \times$ weight $(\mathrm{kg}) \times 0.2 \times(0.85$, if female $)$ [4]. An M/E ratio of $0.9-1.0$ was deemed a complete 24 -hour collection. The paired spot and 24-hour urine collections selected for study were randomly chosen to represent the entire proteinuria range of SLE GN. We analyzed 86 paired spot and intended 24-hour urine collections [11].

C-G is a reliable estimate of 24-hour urine creatinine excretion in European Americans and African Americans with SLE nephritis as shown by the strong global agreement between creatinine clearance estimated from C-G and that directly measured from 24-hour urine collections (e.g., $\mathrm{r}^{2}=0.91$, mean difference between $\mathrm{C}-\mathrm{G}$ and directly measured creatinine clearance $2.4 \mathrm{ml} /$ $\min / 1.73 \mathrm{~m}^{2}$ ) [19].

Study 2 involved biopsy-proven SLE GN patients attending Specialists' Clinics in Hong Kong. They analyzed 129 paired spot and intended 24-hour urine samples from 82 patients. The intended 24-hour urine collections had to contain an amount of creatinine that was not $<0.2 \mathrm{~g}$ of the expected creatinine content based on C-G [15], which is a satisfactory estimate of 24-hour urine creatinine excretion in Asians [20].

Statistical Analyses of the Present Study

To compare the proteinuria data of Study 1 and Study 2, the individual 24-hour proteinuria values of Study 2 were converted to 'imputed' 24-hour $\mathrm{P} / \mathrm{C}$ ratios, as follows. A computer-generated image of figure 1 of Study 2 was enlarged so that as many individual points as possible could be distinguished $(n=113)$, and then rectified so that the horizontal and vertical axes were equal in scale. Using computer-generated coordinates, each point was localized and its coordinates (24-hour proteinuria, spot urine $\mathrm{P} / \mathrm{C}$ ratio) calculated by the computer. To convert the 24 -hour proteinuria values to imputed 24-hour urine $\mathrm{P} / \mathrm{C}$ ratios, we assigned a value of $1.0 \mathrm{~g}$ of creatinine to each of the Study 2 intended 24-hour urine collections. The rationale is that by $\mathrm{C}-\mathrm{G}$, the Study 2 average expected 24-hour urine creatinine excretion was about $0.9 \mathrm{~g} / 24 \mathrm{~h}$. This value was arbitrarily increased to $1.0 \mathrm{~g} / 24 \mathrm{~h}$ to account for the fact that $7 \%$ of the study patients were males, and that the study did not exclude over collections. Thus, for a given Study 2 patient, the imputed 24-hour P/C ratio was the protein content (in grams) of their intended 24-hour urine collection divided by the average 24-hour creatinine excretion (in grams) of the Study 2 cohort.

All mean values are shown \pm 1 SD. 


\section{Results}

Validation of Imputed 24-Hour Urine P/C Ratio as a Surrogate for the Actual 24-Hour Urine P/C Ratio in Determining the Variability between Random Spot and 24-Hour Urine P/C Ratios

Using imputed 24 -hour urine $\mathrm{P} / \mathrm{C}$ ratios introduces biases. For example, if the patient's actual 24 -hour urine creatinine excretion is greater than the average for their cohort, the imputed 24-hour urine $\mathrm{P} / \mathrm{C}$ ratio overestimates the actual 24-hour urine $\mathrm{P} / \mathrm{C}$ ratio. The opposite bias occurs if the actual 24-hour urine creatinine excretion is less than the average of this cohort. Thus, the use of an imputed 24-hour urine $\mathrm{P} / \mathrm{C}$ ratio in place of the true 24-hour urine $\mathrm{P} / \mathrm{C}$ ratio should provide offsetting biases when determining the variability between paired random spot urine $\mathrm{P} / \mathrm{C}$ ratio and 24 -hour urine $\mathrm{P} / \mathrm{C}$ ratio.

To test the above hypothesis, we analyzed the Study 1 database because it provides the actual 24-hour urine P/C ratio, and the imputed 24 -hour urine $\mathrm{P} / \mathrm{C}$ ratios can be calculated. The patients selected were those who had paired random spot and 24-hour urine $\mathrm{P} / \mathrm{C}$ ratio determined in the range of 0 to 4.0, and the actual 24-hour urine collections had $\mathrm{M} / \mathrm{E}$ ratios $\geq 75 \%$. For this cohort, the mean $\mathrm{M} / \mathrm{E}$ ratio was $1.02 \pm 0.21$ and the median $\mathrm{M} / \mathrm{E}$ ratio was 1.00 . Thus, on average, these patients provided a complete 24 -hour urine collection. To calculate the mean 24-hour urine creatinine excretion for this cohort, we used the cohort's mean weight $(79.3 \mathrm{~kg})$, mean age (33.2 years), percent females $91.5 \%$ (statistical weight for C-G 0.85), and percent African Americans 35.2\% (statistical weight for C-G 1.21) [21]. Using those parameters, the calculated mean 24-hour urine creatinine excretion from $\mathrm{C}-\mathrm{G}$ for the cohort was $1.59 \mathrm{~g}$.

Next we displayed graphically the random spot urine $\mathrm{P} / \mathrm{C}$ ratios in relationship to the measured (actual) 24hour urine $\mathrm{P} / \mathrm{C}$ ratios and in relationship to the imputed 24 -hour urine $\mathrm{P} / \mathrm{C}$ ratios. As shown in figure 1, the variability between random spot $\mathrm{P} / \mathrm{C}$ ratio and actual 24 hour urine $\mathrm{P} / \mathrm{C}$ ratio is essentially the same as the variability between random spot $\mathrm{P} / \mathrm{C}$ ratio and imputed 24 hour $\mathrm{P} / \mathrm{C}$ ratio. Thus, imputed 24 -hour urine $\mathrm{P} / \mathrm{C}$ ratio is a valid surrogate for the actual 24-hour urine $\mathrm{P} / \mathrm{C}$ ratio, for the purposes of assessing the variability between random spot urine $\mathrm{P} / \mathrm{C}$ ratio and 24 -hour urine $\mathrm{P} / \mathrm{C}$ ratio. It is essential, however, that the actual 24-hour collections used to calculate imputed $\mathrm{P} / \mathrm{C}$ ratio represent complete or nearly complete 24 -hour collections. These conditions were met in Study 1 (discussed above) and in Study 2 (discussed in Methods).

Spot Urine P/C Ratio

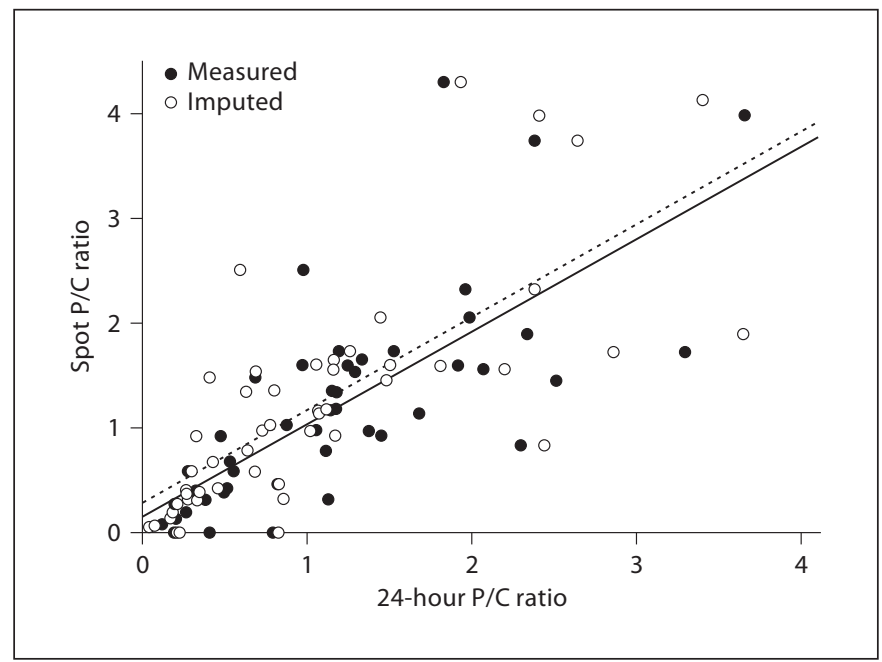

Fig. 1. Comparison of Study 1 random spot urine $\mathrm{P} / \mathrm{C}$ ratios in relationship to the paired actual (measured) 24-hour urine $\mathrm{P} / \mathrm{C}$ ratios (closed circles), and in relationship to the paired imputed 24-hour urine $\mathrm{P} / \mathrm{C}$ ratios (open circles). As shown, the variability between random spot urine $\mathrm{P} / \mathrm{C}$ ratio and measured 24-hour urine $\mathrm{P} / \mathrm{C}$ ratio is similar to the variability between random spot urine $\mathrm{P} / \mathrm{C}$ ratio and imputed 24 -hour urine $\mathrm{P} / \mathrm{C}$ ratio. The regression of random spot urine $\mathrm{P} / \mathrm{C}$ ratio on measured 24-hour urine $\mathrm{P} / \mathrm{C}$ ratio (solid line) is slope 0.884 , intercept $0.156, \mathrm{r}^{2}=0.553$. The regression of random spot urine $\mathrm{P} / \mathrm{C}$ ratio on imputed 24-hour urine $\mathrm{P} / \mathrm{C}$ ratio (dotted line) is slope 0.884 , intercept $0.290, \mathrm{r}^{2}=$ 0.546 .

\section{Comparison of Study 1 and Study 2}

Table 1 shows that the baseline characteristics of Study 1 and Study 2 patients are similar. Figure 2 shows the comparison of Study 1 and Study 2 over the 24-hour urine $\mathrm{P} / \mathrm{C}$ ratio range $0.5-3.0$. A calibration plot [14] is used because 24-hour $\mathrm{P} / \mathrm{C}$ ratio can be regarded as the standard to which random spot $\mathrm{P} / \mathrm{C}$ is to be compared [11]. The calibration plot shows the 24-hour urine $\mathrm{P} / \mathrm{C}$ ratio in relation to the ratio: (spot $\mathrm{P} / \mathrm{C}) /(24$-hour $\mathrm{P} / \mathrm{C}$ ), which is the relative error of random spot $\mathrm{P} / \mathrm{C}$ ratio in estimating 24-hour urine $\mathrm{P} / \mathrm{C}$ ratio. These data are shown in relation to dotted horizontal lines, which are the expected limits of agreement between the random spot $\mathrm{P} / \mathrm{C}$ ratios and the 24-hour urine $\mathrm{P} / \mathrm{C}$ ratios, if random spot $\mathrm{P} / \mathrm{C}$ and 24 -hour urine $\mathrm{P} / \mathrm{C}$ ratios are equally precise in estimating 24-hour proteinuria. The limits of agreement were conservatively set at $\pm 15 \%$. This is a blend of the expected limits of agreement of Study 1 and Study 2. The rationale is as follows. For Study 1, all of the intended 24hour urine collections were $\geq 75 \%$ complete. Intended 24 -hour urine collections that are $>50 \%$ complete pro-

Nephron Clin Pract 2009;113:c177-c182 


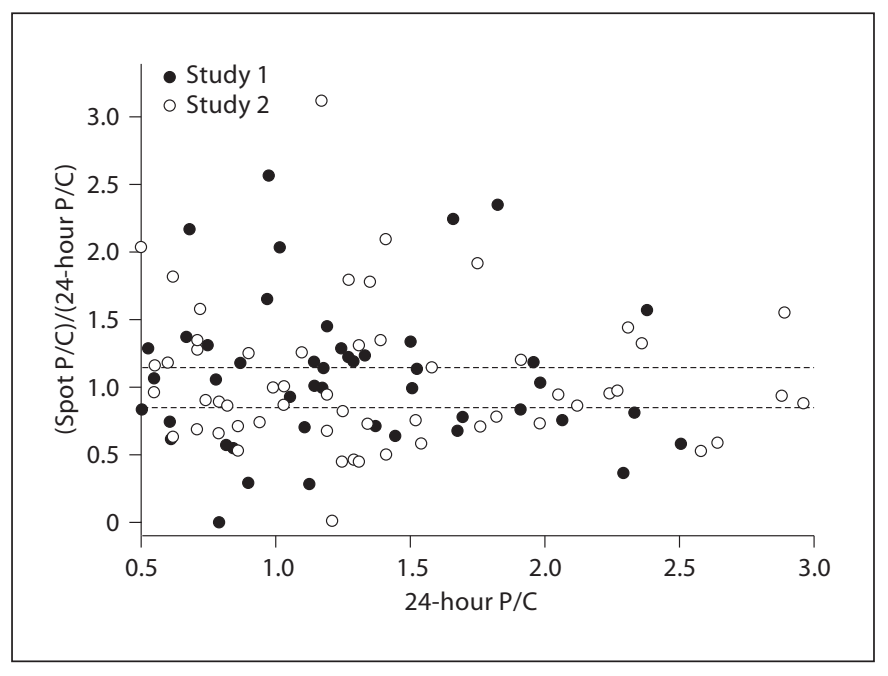

Fig. 2. Relationship between 24 -hour $\mathrm{P} / \mathrm{C}$ ratio and the ratio: (spot $\mathrm{P} / \mathrm{C}) /(24$-hour P/C) for the cohorts of Study 1 (closed circles) and Study 2 (open circles) with $\mathrm{P} / \mathrm{C}$ ratios 0.5 to 3.0. These data are shown in relationship to the expected limits of agreement (dotted horizontal lines) between random spot urine $\mathrm{P} / \mathrm{C}$ ratio and 24 hour urine $\mathrm{P} / \mathrm{C}$ ratio, if they were equally precise in estimating 24-hour proteinuria. See text for further discussion.

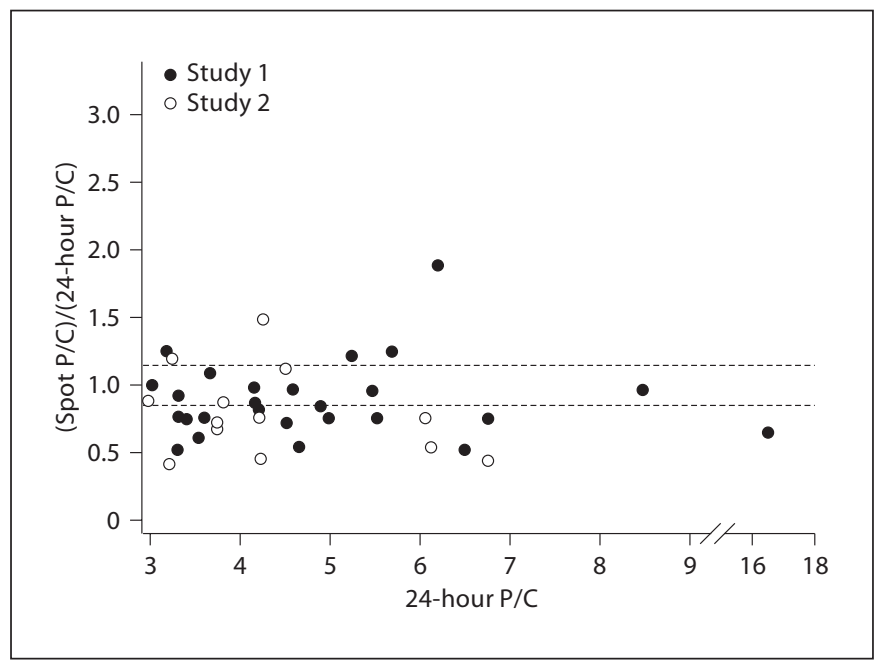

Fig. 3. Relationship between 24-hour P/C ratio and the ratio: (spot $\mathrm{P} / \mathrm{C}) /(24$-hour P/C) for the cohorts of Study 1 (closed circles) and Study 2 (open circles) with $\mathrm{P} / \mathrm{C}$ ratios $>3$. See text for further discussion. The conventions in figure 3 are the same as those in figure 2 .

Table 1. Baseline clinical characteristics of Study 1 and Study 2 patients

\begin{tabular}{|c|c|c|c|c|c|c|c|c|}
\hline & $\mathrm{n}$ & Age, years & $\%$ Female & Weight, kg & S creat ${ }^{\mathrm{a}}$ & $\mathrm{P} / \mathrm{C}^{\mathrm{b}}$ & $\%$ pred $^{\mathrm{c}}$ & $\%$ IS $^{\mathrm{d}}$ \\
\hline Study 1 & 64 & $34 \pm 11$ & 91 & $77.0 \pm 17.2$ & $1.11 \pm 0.6$ & $1.51 \pm 2.36$ & 91 & 88 \\
\hline Study 2 & 82 & $41(32-47)$ & 92.7 & $52.9(48.2-60.0)$ & $74.6(60-104)$ & $0.62(0.2-1.4)$ & 95.3 & 62.9 \\
\hline
\end{tabular}

${ }^{a}$ Serum creatinine, mg/dl. ${ }^{\mathrm{b}}$ Urine P/C ratio (assuming mean 24 -hour creatinine $1,000 \mathrm{mg}$ ) for Study $2 .{ }^{\mathrm{c}}$ Percent receiving prednisone. ${ }^{\mathrm{d}}$ Percent receiving an immunosuppressant.

vide $\mathrm{P} / \mathrm{C}$ ratios that are not significantly different from the $\mathrm{P} / \mathrm{C}$ ratios of collections that are within $\pm 10 \%$ of a complete collection [11]. Thus, for Study 1 the random spot $\mathrm{P} / \mathrm{C}$ ratios should generally be within about $\pm 10 \%$ of the 24 -hour $\mathrm{P} / \mathrm{C}$ ratios, if random spot $\mathrm{P} / \mathrm{C}$ ratio and 24 -hour $\mathrm{P} / \mathrm{C}$ ratio are equally precise in estimating 24 hour proteinuria. For Study 2, the great majority of the intended 24-hour urine collections also represent complete or nearly complete 24 -hour urine collections. However, because this is less clear in Study 2, in interpreting the pooled results of Study 1 and Study 2 the expected limits of agreement were arbitrarily increased to $\pm 15 \%$.

As shown in figure 2, for both Study 1 and Study 2, most of the points fall well outside the limits of agree- ment (67\% for Study 1, 68\% for Study 2). The mean (spot $\mathrm{P} / \mathrm{C}) /(24$-hour P/C) of Study 1 was not different from that of Study 2 (1.09 vs. 1.04 , respectively, $\mathrm{p}=0.535$ by Mann-Whitney nonparametric testing).

Figure 3 shows the proteinuria data of Study 1 and Study 2 for the cohorts with $\mathrm{P} / \mathrm{C}$ ratios $>3.0$. Here, there appears to be better agreement than in figure 2, but this is misleading. Note that the great majority of the points still fall outside the limits of agreement (62\% for Study 1, $69 \%$ for Study 2). Also, the absolute differences are large. For example, in $25 \%$ of the measures, random spot $\mathrm{P} / \mathrm{C}$ ratio underestimates or overestimates 24 -hour proteinuria by $50 \%$ or greater. This corresponds to absolute differences of about 2 to $4 \mathrm{~g} / 24 \mathrm{~h}$. The mean (spot P/C)/(24- 
hour P/C) of Study 1 was not different from that of Study $2(0.89 \pm 0.29$ vs. $0.79 \pm 0.33$, respectively, $\mathrm{p}=0.34$ by unpaired $\mathrm{t}$ test).

Additional statistical description of the discordance between random spot $\mathrm{P} / \mathrm{C}$ ratio and 24 -hour $\mathrm{P} / \mathrm{C}$ ratio was previously reported for Study 1 . There, we documented over the $\mathrm{P} / \mathrm{C}$ ratio range 0.5 to 3.0 low concordance correlation coefficients (CCC) (CCC $=0.479,95 \%$ lower confidence boundary $=0.269)$ and poor ability of random spot $\mathrm{P} / \mathrm{C}$ ratio to predict the actual 24-hour P/C ratio by either linear regression analysis or by an inverse prediction/calibration model [11].

\section{Discussion}

The present work is a reassessment of Study 1 and Study 2, the only published work on the use of random spot urine $\mathrm{P} / \mathrm{C}$ ratio to estimate 24 -hour proteinuria in SLE GN patients. There have been numerous reports on the use of random spot urine $\mathrm{P} / \mathrm{C}$ ratio to estimate 24 hour proteinuria in non-SLE CKD [5, 6]. However, it cannot be assumed that the results of proteinuria testing in non-SLE CKD will be the same as that of SLE GN [22]. Relevant differences include that SLE GN patients are overwhelmingly female, and generally smaller than nonSLE CKD. This results in lower urine creatinine excretion rates in the SLE cohorts. In addition, SLE GN patients are more likely to manifest inflammation, which lowers serum albumin by increasing catabolism [22]. Also, data from SLE mouse models suggest that the renal tubular catabolism of filtered proteins is less than that of non-SLE models of kidney disease [22].

Study 1 concluded that random spot urine $\mathrm{P} / \mathrm{C}$ ratio was unreliable in estimating 24 -hour $\mathrm{P} / \mathrm{C}$ ratio. Study 2 , using Bland-Altman and receiver operator curve analyses, concluded that random spot urine $\mathrm{P} / \mathrm{C}$ ratio was a reliable estimate of 24-hour proteinuria.

The present work shows that Study 1 and Study 2 are, in fact, in good agreement. Over the $\mathrm{P} / \mathrm{C}$ ratio range 0.5-3.0, both Study 1 and Study 2 document that random spot urine $\mathrm{P} / \mathrm{C}$ ratio is an unreliable estimate of 24 -hour urine $\mathrm{P} / \mathrm{C}$ ratio. The degree of unreliability is large and, in individual patients, likely would lead to important diagnostic and therapeutic errors. For example, a BILAG Category A proteinuric flare is indicated when 24 -hour proteinuria increases from $\leq 0.2$ to $>1 \mathrm{~g} /$ day [7]. From inspection of figure 2 , it is clear that random spot urine $\mathrm{P} / \mathrm{C}$ ratios would have difficulty detecting whether a proteinuric flare had occurred. As shown in figure 2, at a 24-hour $\mathrm{P} / \mathrm{C}$ ratio of about 1.0, random spot $\mathrm{P} / \mathrm{C}$ ratio testing produces values that range from nearly 0 to $>3.0$.

Using the same line of reasoning, it is clear that random spot urine $\mathrm{P} / \mathrm{C}$ ratio testing would have difficulty identifying whether other types of BILAG Category A proteinuric flare had occurred (24-hour proteinuria $>1.0$ g increasing by $100 \%$, or newly documented 24 hour proteinuria of $>1.0 \mathrm{~g}$ ) [7], or whether BILAG Category B proteinuric flare had occurred (24-hour urine protein that has increased from $>1 \mathrm{~g}$ by $50 \%$ but less than 100\%) [7].

Random spot $\mathrm{P} / \mathrm{C}$ ratio would also be unreliable in detecting proteinuria flares in SLE GN patients whose baseline proteinuria is in the nephrotic range. For example, as shown in figure 3 , for a patient whose 24 -hour $\mathrm{P} / \mathrm{C}$ ratio is about 4.0 , random spot $\mathrm{P} / \mathrm{C}$ would provide values as low as 2.0 to as high as 6.0. The latter value would be a BILAG Category B flare, the former value would not.

The present work, however, cannot be used to determine the extent to which using random spot urine P/C ratio would confound the accurate management of SLE GN because the present work did not specifically examine random spot $\mathrm{P} / \mathrm{C}$ ratio and 24 -hour urine $\mathrm{P} / \mathrm{C}$ ratio in relationship to flares. That will require a separate study.

The greater reliability of an intended 24-hour collection to estimate 24 -hour $\mathrm{P} / \mathrm{C}$ ratio can be expected because the $\mathrm{P} / \mathrm{C}$ ratio of an intended 24-hour collection is the integrated mean of multiple spot urine $\mathrm{P} / \mathrm{C}$ ratios, which are intrinsically 'bouncy' even under conditions that maximize proteinuria stability [5]. An intended 24hour urine that is at least $50 \%$ complete averages those bounces to provide a reliable estimate of the true 24-hour urine $\mathrm{P} / \mathrm{C}$ ratio.

Recent work suggests that urine collection periods that are longer than spot collections but shorter than intended 24-hour collections may also reliably estimate 24hour proteinuria. These include overnight collections [23] or collections over about 08.00 to 14.00 or 12.00 to $24.00 \mathrm{~h} \mathrm{[24]}$. The caveat with using shorter urine collection periods to assess proteinuria in individual patients is that minor changes in the patients' usual routine could importantly influence the protein or creatinine content of the shorter collection. Such changes could include nocturia, diet (salt or protein intake), medication timing, exercise, posture, body temperature (e.g., fever) $[4,5,11]$, or whether the urine contains semen [25-27]. 


\section{Conclusion}

Random spot urine $\mathrm{P} / \mathrm{C}$ ratio is unreliable in monitoring proteinuria changes in individual SLE GN patients. It is also unreliable as a screening test. Underestimates and overestimates occur with about equal frequency. The recommended method to monitor proteinuria in SLE GN is from intended 24-hour urines that are at least $50 \%$ complete based on their creatinine content. Such collections provide a $\mathrm{P} / \mathrm{C}$ ratio that is not significantly different from the $\mathrm{P} / \mathrm{C}$ ratios of complete 24 -hour urine collections.
Based on recent reports, further study of overnight and 6-hour or 12 -hour collections to estimate 24 -hour proteinuria in individual nephritis patients is warranted.

\section{Acknowledgements}

This work was supported in part by National Institute of Health grants: PO1 DK55546, UL-1-RR025755, 1R21DK07731; the Lupus Clinical Trials Consortium, and the James D. Casto Fund.

\section{References}

1 Peterson JC, Adler S, Burkart JM, Greene T, Hebert LA, Hunsicker LG, King AJ, Klahr S, Massry SG, Seifter JL: Blood pressure control, proteinuria, and the progression of renal disease. The Modification of Diet in Renal Disease Study. Ann Intern Med 1995;123: 754-762.

-2 GISEN: Randomised placebo-controlled trial of effect of ramipril on decline in glomerular filtration rate and risk of terminal renal failure in proteinuric, non-diabetic nephropathy. The GISEN Group (Gruppo Italiano di Studi Epidemiologici in Nefrologia). Lancet 1997;349:1857-1863.

3 Rossing P, Hommel E, Smidt UM, Parving $\mathrm{HH}$ : Reduction in albuminuria predicts a beneficial effect on diminishing the progression of human diabetic nephropathy during antihypertensive treatment. Diabetologia 1994;37:511-516.

-4 Wilmer WA, Rovin BH, Hebert CJ, Rao SV, Kumor K, Hebert LA: Management of glomerular proteinuria: a commentary. J Am Soc Nephrol 2003;14:3217-3232.

-5 Shidham G, Hebert LA: Timed urine collections are not needed to measure urine protein excretion in clinical practice. Am J Kidney Dis 2006;47:8-14.

-6 Gaspari F, Perico N, Remuzzi G: Timed urine collections are not needed to measure urine protein excretion in clinical practice. Am J Kidney Dis 2006;47:1-7.

-7 Gordon C, Sutcliffe N, Skan J, Stoll T, Isenberg DA: Definition and treatment of lupus flares measured by the BILAG index. Rheumatology (Oxford) 2003;42:1372-1379.

8 NKF: K/DOQI clinical practice guidelines on hypertension and antihypertensive agents in chronic kidney disease. Am J Kidney Dis 2004;43(5 suppl 1):S1-S290.

-9 Austin HA: Clinical evaluation and monitoring of lupus kidney disease. Lupus 1998;7: 618-621.

$\checkmark 10$ Levey AS, Coresh J, Balk E, Kausz AT, Levin A, Steffes MW, Hogg RJ, Perrone RD, Lau J,
Eknoyan G: National Kidney Foundation practice guidelines for chronic kidney disease: evaluation, classification, and stratification. Ann Intern Med 2003;139:137-147.

-11 Birmingham DJ, Rovin BH, Shidham G, Nagaraja HN, Zou X, Bissell M, Yu CY, Hebert LA: Spot urine protein/creatinine ratios are unreliable estimates of $24 \mathrm{~h}$ proteinuria in most systemic lupus erythematosus nephritis flares. Kidney Int 2007;72:865-870.

12 Ginsberg JM, Chang BS, Matarese RA, Garella S: Use of single voided urine samples to estimate quantitative proteinuria. $\mathrm{N}$ Engl J Med 1983;309:1543-1546

13 Renal Disease Subcommittee of the American College of Rheumatology Ad Hoc Committee on Systemic Lupus Erythematosus Response Criteria. The American College of Rheumatology response criteria for proliferative and membranous renal disease in systemic lupus erythematosus clinical trials. Arthritis Rheum 2006;54:421-532.

14 van Stralen KJ, Jager KJ, Zoccali C, Dekker FW: Agreement between methods. Kidney Int 2008;74:1116-1120.

15 Leung YY, Szeto CC, Tam LS, Lam CW, Li EK, Wong KC, Yu SW, Kun EW: Urine protein-to-creatinine ratio in an untimed urine collection is a reliable measure of proteinuria in lupus nephritis. Rheumatology (Oxford) 2007;46:649-652.

16 Rovin BH, Song H, Birmingham DJ, Hebert LA, Yu CY, Nagaraja HN: Urine chemokines as biomarkers of human SLE activity. J Am Soc Nephrol 2005;16:467-473.

$\checkmark 17$ Birmingham DJ, Nagaraja HN, Rovin BH, Spetie L, Zhao Y, Li X, Hackshaw KV, Yu CY, Malarkey WB, Hebert LA: Fluctuation in self-perceived stress and increased risk of flare in patients with lupus nephritis carrying the serotonin receptor $1 \mathrm{~A}-1019 \mathrm{G}$ allele. Arthritis Rheum 2006;54:3291-3299.

18 Rovin BH, Song H, Hebert LA, Nadasdy T, Nadasdy G, Birmingham DJ, Yung Yu C, Nagaraja HN: Plasma, urine, and renal expres- sion of adiponectin in human systemic lupus erythematosus. Kidney Int 2005;68:18251833.

19 Kasitanon N, Fine DM, Haas M, Magder LS, Petri M: Estimating renal function in lupus nephritis: comparison of the Modification of Diet in Renal Disease and Cockcroft Gault equations. Lupus 2007;16:887-895.

20 Leung YY, Lo KM, Tam LS, Szeto CC, Li EK, Kun EW: Estimation of glomerular filtration rate in patients with systemic lupus erythematosus. Lupus 2006;15:276-281.

21 Stevens LA, Coresh J, Greene T, Levey AS: Assessing kidney function - measured and estimated glomerular filtration rate. $\mathrm{N}$ Engl J Med 2006;354:2473-2483.

22 Birmingham DJ, Rovin BH, Shidham G, Bissell M, Nagaraja HN, Hebert LA: Relationship between albuminuria and total proteinuria in systemic lupus erythematosus nephritis: diagnostic and therapeutic implications. Clin J Am Soc Nephrol 2008;3:10281033.

23 Witte EC, Lambers Heerspink HJ, de Zeeuw D, Bakker SJ, de Jong PE, Gansevoort R: First morning voids are more reliable than spot urine samples to assess microalbuminuria. J Am Soc Nephrol 2009;20:436-443.

24 Fine DM, Ziegenbein M, Petri M, Han E, McKinley AM, Chellini J, Nagaraja HN, Carson KA, Rovin BH: Estimation of daily protein excretion in patients with lupus nephritis using short-interval timed urine collections. Kidney Int, in press.

25 Domachevsky L, Grupper M, Shochat T, Adir Y: Proteinuria on dipstick urine analysis after sexual intercourse. BJU Int 2006;97: 146-148.

26 Riches P, Rippin J, Walker S: Seminal fluid contamination of urine. Ann Clin Biochem 1993:30:228-230

$\checkmark 27$ Hirsch IB, Farkas-Hirsch R, Herbst JS, Skyler JS: The effect of ejaculation on albumin excretion rate. J Diabetes Complications 1992;6:163-165. 